\title{
The Impact of Electronic Media on Patients with Inflammatory Bowel Disease
}

This article was published in the following Dove Press journal:

Risk Management and Healthcare Policy

\author{
Dídia B Cury $\mathbb{( D}^{1,2}$ \\ Loyná E Flores Paez' \\ Ana C Micheletti ${ }^{3}$ \\ Sabrina T Reis ${ }^{4}$ \\ 'Inflammatory Bowel Disease Center, \\ Scope Clinic, Campo Grande, MS, Brazil; \\ ${ }^{2}$ Center for Crohn's and Colitis, Brigham \\ and Women's Hospital, Harvard Medical \\ School, Boston, MA, USA; ${ }^{3}$ nstitute of \\ Chemistry, Federal University of Mato \\ Grosso do Sul, Campo Grande, MS, \\ Brazil; ${ }^{4}$ Laboratory of Medical \\ Investigation 55 (LIM55) - Urology \\ Department, University of São Paulo \\ Medical School, São Paulo, SP, Brazil
}

Correspondence: Dídia B Cury Inflammatory Bowel Disease Center, Scope Clinic, Maracaju Street II48, Campo Grande, MS, 79002-212, Brazil Tel +55 6733256040

Email didiacury@gmail.com
Introduction and Objectives: Patients with chronic illnesses, such as inflammatory bowel disease (IBD), may often consult the internet, which can cause anguish, fear, stress and anxiety. The aim of our study is to evaluate the use of the internet and its effects on patients with IBD.

Patients and Methods: This is a descriptive, cross-sectional study with quantitative frequency analysis. We applied a questionnaire comprising questions about internet use, and the DASS21 questionnaire to analyze internet impact on patients' stress and/or anxiety for 36 months.

Results: A total of 104 patients were included over a period of 45 days ( $82 \% \mathrm{CD}, 18 \% \mathrm{UC})$. The mean age was 41.3 years $( \pm 15.9$ years). Internet use was more frequent in patients with a mean age of 39.5 years ( \pm 14.4 years), with the highest frequencies found in the age group of $26-36$ years. Internet use were related to: $72.6 \%$ general information about the disease, $87.3 \%$ symptom information ( $42.1 \%$ once a week, $27.4 \%$ never, $18.8 \%$ once a month, $10.5 \%$ daily, and 3.2\% twice a day). The most visited search engine was Google $63.7 \%$ and the most visited sites were: patient group sites $16.7 \%$, health sites $16.2 \%$ medical sites $12.8 \%$.

Conclusion: The internet is often a resource utilized by patients with IBD and although these patients sought to obtain more information about their disease and their symptoms. The internet was not a factor influencing anxiety and stress for these patients.

Keywords: inflammatory bowel disease, electronic media, internet, Brazil

\section{Introduction and Objectives}

Studies have demonstrated that searches for information on the internet, mainly when a new symptom arises, have been reported in Health Service Centers all over the world. ${ }^{1-3}$ The internet can either help patients with their doubts or increase their stress. ${ }^{4}$

Inflammatory Bowel Diseases (IBD) are chronic diseases that can often contribute to high levels of anguish, fear, stress and anxiety. Therefore, search for information on the internet is increasingly being described by patients with chronic diseases. $^{4,5}$ It is also common that patients with chronic illnesses create WhatsApp groups and exchange information about the disease, prescribed drugs and their own doctors. ${ }^{6}$

Some positive aspects of patient initiated research include access to information about health issues, comfort from a community of other people with similar issues. Negative aspects may include accentuation of symptoms or somatization. ${ }^{7}$

On the other hand, health professional-managed support groups and resources can help these patients reduce stress and understand how to live better with the disease. These support groups can also generate indices to be used in research on 
the quality of life of these patients. ${ }^{8,9}$ The internet may or may not be an auxiliary tool for these patients, depending on how it is used or understood by them.

As medical information becomes accessible online, we ask the question of how patients use this tool, whether it impacts the patient positively or negatively, how it helps in the treatment and understanding of disease, whether it contributes to a change in behavior of patients, and how it relates to patient stress, anxiety, and depression. The impacts of the doctor-patient relationship were also assessed.

The objectives of this research were evaluate the use of the internet and the frequency with which it is used by patients with inflammatory bowel disease, analyze the effect of positive (better understanding of the disease) and negative (increased stress, medication changes, anxiety, and non-adherence) impacts on the patient, check the reliability of the internet and the types of websites most searched by Brazilian patients and find out if internet information can change the patient-doctor relationship.

\section{Patients and Methods}

\section{Questionnaire and Patients}

Preparation and Application of the Media

\section{Questionnaire}

Over three years, we collected information reported from patients regarding their use of the internet, and based on the data we developed a questionnaire about it (Q1 Supplementary material).

To analyze the patients' behavior, we considered the anxiety aspect. For this analysis, we applied Depression, Anxiety and Stress Scale-Short Form (DASS-21), a questionnaire encompassing questions about internet use and the analysis of its impact producing stress or anxiety.

Patients were invited to participate in the study at the time of their attendance at the Inflammatory Bowel Disease Center, for follow-up consultations, and all participants provided informed consent. A total of 104 patients were included over a period of 45 days.

\section{Inclusion and Exclusion Criteria}

Patients with Crohn's disease and ulcerative colitis who are followed up at the Inflammatory Bowel Disease Center, Scope Clinic. Patients who did not accept to participate in the study were excluded.

\section{Statistical Analysis}

The variables were initially analyzed using the values of mean, standard deviation, median, minimum and maximum, absolute frequency and percentage. To compare the groups in relation to the Depression, Anxiety and Stress Scale (DASS21 questionnaire), the nonparametric Mann-Whitey test was used. The software used was SPSS17.0 for Windows and a significance level of $5 \%$ was used for the tests.

\section{Ethical Considerations}

The research complies with current regulations on bioethical research and it obtained the authorization of the institution's ethics committee of the Federal University of Mato Grosso do Sul under the number 3.354.481. This study was conducted in accordance with the Declaration of Helsinki.

\section{Results}

Of the total sample (104 patients), $72.6 \%$ use the internet for general disease information, $87.3 \%$ for symptom information ( $42.1 \%$ once a week, $27.4 \%$ never, $18.8 \%$ once a month, daily $10.5 \%, 3.2 \%$ twice a week), and the median age was of 37 years (Table 1). The main search engine was Google $63.7 \%$ and the most visited internet sites were: $16.7 \%$ patient groups, $16.2 \%$ health sites (non-scientific sites related to health and well-being), $12.8 \%$ medical sites (scientific ones, such as Pubmed, websites of medical institutions or study groups), among others (Table 2). From the search objectives: Additional Information $60 \%$, to learn about other patients' stories $36.6 \%$ (to compare to their own stories), new information $12.8 \%$, information about prescription $12.9 \%$ (Table 3). Regarding the level of patients' confidence in the information obtained, $61.4 \%$ believe in the information extracted from internet research (Table 4).

Table I Absolute and Relative Frequencies of Specific Internet Use for the Disease

\begin{tabular}{|l|l|l|l|}
\hline Internet Use & Classification & $\mathbf{n}$ & $\%$ \\
\hline For any use & Never & 10 & 9.8 \\
& I-2 times per month & 6 & 5.9 \\
& Once per week & 2 & 2.0 \\
& Twice per week & I & 1.0 \\
& Daily & 53 & 52.0 \\
& More than once a day & 30 & 29.4 \\
\hline \multirow{2}{*}{ To search about IBD } & Never & 26 & 27.4 \\
& I-2 times per month & 16 & 16.8 \\
& Once per week & 40 & 42.1 \\
& Twice per week & 3 & 3.2 \\
& Daily & 10 & 10.5 \\
& More than once a day & 0 & 0.0 \\
\hline
\end{tabular}


Table 2 Absolute and Relative Frequencies of Searched Sites

\begin{tabular}{|l|l|l|}
\hline Site & $\mathbf{n}$ & $\%$ \\
\hline Do not look & 18 & 17.8 \\
Medical sites & 13 & 12.8 \\
Disease sites & 9 & 8.8 \\
Universities & 9 & 8.8 \\
Google & 65 & 63.7 \\
Youtube & 14 & 13.7 \\
Facebook & 12 & 11.8 \\
Yahoo & 2 & 2.0 \\
WhatsApp & 7 & 6.9 \\
Patients groups & 17 & 16.7 \\
Other health sites & 16 & 16.2 \\
\hline
\end{tabular}

Table 3 Absolute and Relative Frequencies of the Reasons That Lead the Patient to Search the Internet

\begin{tabular}{|l|l|l|}
\hline Reason & $\mathbf{n}$ & $\%$ \\
\hline Understand better & 8 & 8.5 \\
Ashamed asking & 0 & 0.0 \\
Complement information & 57 & 60.6 \\
Understand read & 5 & 5.3 \\
To hear others patients & 34 & 36.6 \\
Check information & 4 & 4.3 \\
New information & 12 & 12.8 \\
Information prescribed & 12 & 12.9 \\
Ask the question to the doctor & $\mathrm{I}$ & 1.0 \\
Curiosity & $\mathrm{I}$ & 1.0 \\
\hline
\end{tabular}

Positive aspects: Of the 43 patients who said they were influenced by the internet, $41.9 \%$ reported feeling calmer and $41.9 \%$ reported handling the disease better. Negative aspects: among these 43 patients, $11.6 \%$ felt more stressed. Behavior change in the doctor-patient relationship: $23.3 \%$ began to question the doctor a bit more; $0 \%$ had their medication changed; influence on the doctor's choice: $4.7 \%$ of the sample were being followed at that center due to internet searches (Table 4). When applying DASS-

Table 4 Absolute and Relative Frequencies of the Type of Influence When the Patient Searches the Internet, in the 43 Cases That Were Influenced by It

\begin{tabular}{|l|l|l|}
\hline Influence & $\mathbf{n}$ & $\%$ \\
\hline Calm me down & 18 & 41.9 \\
Stress me & 5 & 11.6 \\
Question doctor & 10 & 23.3 \\
Choose doctor & 2 & 4.7 \\
Change medicine & 0 & 0.0 \\
Handle disease & 18 & 41.9 \\
\hline
\end{tabular}

21 no statistical significance was found between internet use and anxiety or stress worsening (Tables 5 and 6).

\section{Discussion}

The use of the internet may impact the patients' treatment, especially in patients with chronic diseases and may even affect the patient-doctor relationship. ${ }^{10,11}$ Some studies have suggested the potential risk of mobile phones in affecting people's mental health, inducing greater anxiety. ${ }^{12,13}$ Conversely, in patients with psychosis, the search for "Dr. Google" has helped by contributing both to the primary

Table 5 Descriptive Values of DASS-2I Constructs for the Group of Patients That Uses Internet to Obtain Knowledge About Symptoms

\begin{tabular}{|c|c|c|c|c|}
\hline \multirow[t]{2}{*}{ Construct } & & \multicolumn{2}{|c|}{$\begin{array}{l}\text { Use Internet to Obtain } \\
\text { Knowledge About the } \\
\text { Symptoms }\end{array}$} & \multirow[t]{2}{*}{$\mathbf{p}^{*}$} \\
\hline & & No & Yes & \\
\hline Stress & $\begin{array}{c}\text { Median } \\
\text { (QI; Q3) }\end{array}$ & $\begin{array}{c}4.0 \\
(2.0 ; 11.0)\end{array}$ & $\begin{array}{c}5.0 \\
(2.0 ; 9.0)\end{array}$ & 0.684 \\
\hline Anxiety & $\begin{array}{c}\text { Median } \\
\text { (QI; Q3) }\end{array}$ & $\begin{array}{c}4.5 \\
(0.5 ; 7.0)\end{array}$ & $\begin{array}{c}2.0 \\
(0.0 ; 6.0)\end{array}$ & 0.321 \\
\hline Depression & $\begin{array}{c}\text { Median } \\
\text { (QI; Q3) }\end{array}$ & $\begin{array}{c}4.0 \\
(2.0 ; 9.0)\end{array}$ & $\begin{array}{c}3.0 \\
(1.0 ; 7.0)\end{array}$ & 0.396 \\
\hline Total & $\begin{array}{c}\text { Median } \\
\text { (QI; Q3) }\end{array}$ & $\begin{array}{c}10.5 \\
(6.0 ; 25.0)\end{array}$ & $\begin{array}{c}\text { II.5 } \\
(4.0 ; 20.0)\end{array}$ & 0.771 \\
\hline
\end{tabular}

Notes: *p-value nonparametric Mann-Whitney test; QI, lower quartile; Q3, upper quartile.

Table 6 Descriptive Values of the DASS-2I Constructs, According to the Frequency of Internet Use Group for IBD Knowledge

\begin{tabular}{|c|c|c|c|c|}
\hline \multirow[t]{2}{*}{ Construct } & & \multicolumn{2}{|c|}{ IBD Information } & \multirow[t]{2}{*}{$\mathbf{p}^{*}$} \\
\hline & & Never & More Than One Time & \\
\hline Stress & $\begin{array}{l}\text { Median } \\
\text { (QI; Q3) }\end{array}$ & $\begin{array}{c}3.0 \\
(2.0 ; 9.0)\end{array}$ & $\begin{array}{c}5.0 \\
(3.0 ; 9.0)\end{array}$ & 0.194 \\
\hline Anxiety & $\begin{array}{l}\text { Median } \\
\text { (QI; Q3) }\end{array}$ & $\begin{array}{c}1.0 \\
(0.0 ; 5.0)\end{array}$ & $\begin{array}{c}3.0 \\
(0.0 ; 6.0)\end{array}$ & 0.438 \\
\hline Depression & $\begin{array}{l}\text { Median } \\
\text { (QI; Q3) }\end{array}$ & $\begin{array}{c}2.0 \\
(0.0 ; 4.0)\end{array}$ & $\begin{array}{c}4.0 \\
(1.0 ; 7.0)\end{array}$ & 0.063 \\
\hline Total & $\begin{array}{l}\text { Median } \\
\text { (QI; Q3) }\end{array}$ & $\begin{array}{c}7.0 \\
(2.0 ; 17.0)\end{array}$ & $\begin{array}{c}14.0 \\
(5.0 ; 23.0)\end{array}$ & 0.121 \\
\hline
\end{tabular}

Notes: *p-value nonparametric Mann-Whitney test; QI, lower quartile; Q3, upper quartile. 
treatment (search for professionals) and the treatment of the disease. ${ }^{14}$

Over the years the use of the internet by patients with inflammatory bowel disease has been reported in clinical consultations and as IBD is a chronic disease, it is possible that these patients be more susceptible to develop stress and anxiety in the face of internet information. ${ }^{15}$

We have observed the increasing use of "Dr. Google" to clarify doubts as well as to indicate with whom to treat. Based on information from the patients themselves, questionnaires with multiple choice questions and answers were prepared and applied before the consultation (Q1Supplementary material). To analyze the anxiety aspect we applied Depression, Anxiety and Stress Scale-Short Form (DASS-21). The choice of this instrument is justified by involving a theoretical model that discriminates symptoms of anxiety and depression well, not always differentiated by other scales or instruments. The DASS- 21 was developed by Lovibond and Lovibond $(1995)^{16}$ to measure and differentiate, as much as possible, the symptoms of anxiety and depression. The scale is based on the tripartite model, in which depression and anxiety symptoms are grouped into three basic structures. The first one (a) defined by the presence of negative affectivity, such as depressed mood, insomnia, discomfort and irritability, which are all nonspecific symptoms present in both depression and anxiety; the second (b) encompasses factors which constitute specific symptoms of depression (anhedonia, lack of positive affectivity); finally, the last structure (c) relates to the symptoms which are specific to anxiety (somatic anxiety and hyperactivity)

Here, during 45 days, $72.6 \%$ of them used the internet for general information on the disease, while $87.3 \%$ sought information on symptoms. Symptoms turned out to be the reason that most induced patients to look for "Dr. Google" and the main focus was to complement the medical consultation. The most patients believed in the truthfulness of the information viewed on the Internet generally without verifying the reliability of the information on scientific websites. Interestingly, in this group of patients, the side effects of medications did not prove to be a worrying factor and we believe this fact to be very positive, as it could demonstrate the patient's confidence in the doctor without the need to seek for further information.

The use of the internet led to a change in behavior in the doctor-patient relationship, where $23.3 \%$ reported that through this search they began to ask the doctor more questions about the disease. However, this change in behavior was not enough for the patients to change the prescribed medication or even to change doctors. Regarding medical choice $4.7 \%$ of the sample had chosen the doctor based on internet information. When analyzing the psychological aspects (stress, anxiety and depression), no statistical significance was found between internet use and the worsening of anxiety or stress, as well as treatment change, what can be related to an open and reliable patient-physician relationship, when patients are confident to clear questions and doubts.

This study highlights the importance of the patient-physician relationship with current technologies, demonstrating that when it is good the use of the internet does not affect patients' stress or anxiety. We could observe this factor by analyzing that these patients changed neither their medication nor their doctors. The fact that most patients search for their symptoms by using electronic media do not seem to affect the relationship between the patients and their doctors. On the contrary, the patients feel more confident in questioning them. These observations agree with an extensive review published by Kernebeck et al (2020). ${ }^{17}$

\section{Conclusion}

Although the use of the internet is an important vehicle for information, for the studied population it was not observed to be decisive in finding a doctor, nor can it induce negative factors, such as change in therapy, anxiety and insecurity. The search for information, even in non-scientific websites, induced the patients to have greater freedom in the consultation to question their doctors and perhaps strengthened the patient-doctor relationship, clarifying doubts about the disease, its evolution, as well as its treatment.

\section{Abbreviations}

DASS-21, Depression, Anxiety and Stress Scale - Short Form; IBD, inflammatory bowel diseases.

\section{Data Sharing Statement}

The datasets used and/or analysed during the current study are available the corresponding author on reasonable request.

\section{Ethics Approval}

This study was submitted and approved by the Research Ethics Committee of the Federal University of Mato Grosso do Sul under the number 3.354.481.

\section{Acknowledgments}

We thank Sônia Friedman, Rachael Winter from Harvard Medical School. We thank Isabela Salinas, Maria dos 
Santos and Nubia Gomes secretaries from IBD Center Scope. We thank Prof. Dr. Elaine Corti, journalist and professor at Anhembi Morumbi University. We thank Dr. Alejandro Vera, psychiatrist specializing in digital media of Federal University of São Paulo (Unifesp).

\section{Funding}

The research did not receive any specific funding.

\section{Disclosure}

The authors declare that they have no conflict of interests for this work.

\section{References}

1. Gandy M, Karin E, Jones MP, et al. Exploring psychological mechanisms of clinical response to an internet-delivered psychological pain management program. Eur J Pain. 2018;22(8):1502-1516. doi:10.1002/ejp.1239

2. McCullough MB, Chou AF, Solomon JL, et al. The interplay of contextual elements in implementation: an ethnographic case study. BMC Health Serv Res. 2015;15:62. doi:10.1186/s12913-015-0713-7

3. Sassenberg K, Greving H. Internet searching about disease elicits a positive perception of own health when severity of illness is high: a longitudinal questionnaire study. J Med Internet Res. 2016;18(3): e56. doi: $10.2196 /$ jmir.5140

4. Merolli M, Gray K, Martin-Sanchez F, Lopez-Campos G. Patientreported outcomes and therapeutic affordances of social media: findings from a global online survey of people with chronic pain. $\mathrm{J} \mathrm{Med}$ Internet Res. 2015;17(1):e20. doi:10.2196/jmir.3915

5. Merolli M, Gray K, Martin-Sanchez F. Health outcomes and related effects of using social media in chronic disease management: a literature review and analysis of affordances. J Biomed Inform. 2013;46(6):957-969. doi:10.1016/j.jbi.2013.04.010

6. Merolli M, Gray K, Martin-Sanchez F. Therapeutic affordances of social media: emergent themes from a global online survey of people with chronic pain. J Med Internet Res. 2014;16(12):e284. doi:10.2196/ jmir.3494
7. Dent J. Approaches to oesophageal columnar metaplasia (Barrett's oesophagus). Scand J Gastroenterol Suppl. 1989;168:60-66.

8. Nguyen DL, Rasheed S, Parekh NK. Patterns of Internet use by gastroenterologists in the management and education of patients with inflammatory bowel disease. South Med J. 2014;107 (5):320-323. doi:10.1097/SMJ.0000000000000107

9. Matsumoto T, Yanai S, Toya Y, Ueno M, Nakamura S. Internetorientated assessment of QOL and actual treatment status in Japanese patients with inflammatory bowel disease: the 3I survey. J Crohns Colitis. 2015;9(6):477-482. doi:10.1093/ecco-jcc/jjv052

10. Zhao X, Mao Y. Trust me, I am a doctor: discourse of trustworthiness by Chinese doctors in online medical consultation. Health Commun. 2019;1-9. doi:10.1080/10410236.2019.1692491

11. Umefjord G, Petersson G, Hamberg K. Reasons for consulting a doctor on the Internet: web survey of users of an ask the doctor service. J Med Internet Res. 2003;5(4):e26. doi:10.2196/jmir.5.4.e26

12. Franck C, Poulsen MH, Karampas G, Giraldi A, Rudnicki M. Questionnaire-based evaluation of sexual life after laparoscopic surgery for endometriosis: a systematic review of prospective studies. Acta Obstet Gynecol Scand. 2018;97(9):1091-1104. doi:10.1111/ aogs. 13369

13. Vahedi Z, Saiphoo A. The association between smartphone use, stress, and anxiety: a meta-analytic review. Stress Health. 2018;34 (3):347-358. doi:10.1002/smi.2805

14. Kirschenbaum MA, Birnbaum ML, Rizvi A, Muscat W, Patel L, Kane JM. Google search activity in early psychosis: a qualitative analysis of internet search query content in first episode psychosis. Early Interv Psychiatry. 2019;14(5):606-612. doi:10.1111/eip.12886

15. Thakur ER, Sansgiry S, Kramer JR, et al. The incidence and prevalence of anxiety, depression, and post-traumatic stress disorder in a national cohort of US veterans with inflammatory bowel disease. Inflamm Bowel Dis. 2020;26:1423-1428. doi:10.1093/ibd/izz280

16. Lovibond P, Lovibond S. The structure of negative emotional states: comparison of the depression anxiety stress scales (DASS) with the Beck Depression and Anxiety Inventories. Behav Res Ther. 1995;33 (3):335-343. doi:10.1016/0005-7967(94)00075-u

17. Kernebeck S, Busse TS, Böttcher MD, Weitz J, Ehlers J, Bork U. Impact of mobile health and medical applications on clinical practice in gastroenterology. World J Gastroenterol. 2020;26(29):4182-4197. doi:10.3748/wjg.v26.i29.4182
Risk Management and Healthcare Policy

\section{Publish your work in this journal}

Risk Management and Healthcare Policy is an international, peerreviewed, open access journal focusing on all aspects of public health, policy, and preventative measures to promote good health and improve morbidity and mortality in the population. The journal welcomes submitted papers covering original research, basic science, clinical \& epidemiological studies, reviews and evaluations, guidelines, expert opinion and commentary, case reports and extended reports. The manuscript management system is completely online and includes a very quick and fair peer-review system, which is all easy to use. Visit http://www.dovepress.com/testimonials.php to read real quotes from published authors. 